\title{
Lead and cadmium in maternal blood and placenta in pregnant women from a mining-smelting zone of Peru and transfer of these metals to their newborns
}

\author{
Castro Jorge $^{1 \star}$, López de Romaña Daniel ${ }^{2}$, Bedregal Patricia ${ }^{3}$, López de Romaña Guillermo4, \\ Chirinos Doris ${ }^{1}$ \\ ${ }^{1}$ Maestría en Seguridad Alimentaria Nutricional, Universidad Nacional del Centro del Perú, Huancayo, Peru. \\ ${ }^{2}$ Instituto de Investigación Nutricional, Lima, Perú. \\ ${ }^{3}$ Instituto Peruano de Energía Nuclear, Lima, Perú. \\ ${ }^{4}$ Instituto de Seguridad Alimentaria y Nutrición, Universidad Nacional Agraria La Molina, Lima, Perú.
}

Accepted 15 July, 2013

\begin{abstract}
The present study was carried out to determine the lead and cadmium concentration in maternal and umbilical cord blood and placental tissue and breast milk, evaluating forty deliveries with normal evolution of pregnant women living in a mining-smelting town in Peru. In this study, mean concentration of lead in the blood of both women and their neonates were $27.2 \pm 15.9$ and $18.5 \pm 13.0$ $\mu \mathrm{g} / \mathrm{dl}$, respectively with $83 \%$ of the women and $65 \%$ of the neonates having toxic levels. Mean cadmium concentrations in maternal blood were below the safe upper limit, but $45 \%$ of women had levels above $10 \mu \mathrm{g} / \mathrm{dl}$. On the other hand, the mean cadmium concentration in umbilical cord blood was $12.0 \pm 17.8$ $\mu \mathrm{g} / \mathrm{dl}$, with $38 \%$ of neonates having levels above $10 \mu \mathrm{g} / \mathrm{dl}$. The mean concentrations of lead and cadmium in maternal milk were $108.9 \pm 69.4$ and $5.6 \pm 4.3 \mu \mathrm{g} / \mathrm{dl}$, respectively. In addition, lead and cadmium in cord blood accounted for 67.8 and $136.4 \%$ compared to concentrations in maternal blood. There was negative relationship between the concentration of lead in the umbilical cord blood and the birth weight of the neonate $(p=0.006)$. From this study, it is evident that lead contamination and to lesser extent cadmium, pose a problem in pregnant women in this region. In addition, although the placenta appears to act as a protective barrier to the fetus, transfers of these metals to the fetus still persist. Furthermore, the concentration of lead was quite high in maternal milk and could be an important source of contamination to the infant. Finally, there was a negative association between the levels of lead in the umbilical cord blood and the birth weight.
\end{abstract}

Key words: Lead in umbilical cord blood, cadmium in umbilical cord blood, lead in maternal milk, cadmium in maternal milk, lead in placenta, cadmium in placenta, mining-smelting town.

\section{INTRODUCTION}

Lead contamination has been related to a number of health problems, growth and psychomotor retardation in children, alterations in hearing, hematopoietic, central and peripheral nervous system, urinary, gastrointestinal, cardiovascular and endocrine system in adults
(Needleman, 1998). Furthermore, carcinogenic, neurological damages, and cognitive and behavioral alterations have been linked to lead toxicity (Corey and Galvão, 1989). Lead contamination during pregnancy has been shown to increase the risk for abortions, premature 
births and prenatal deaths (Andrews et al., 1994) and weight, height and head circumference of newborns (Osman et al., 2000).

Lead enters the organism mainly via breathing, and through skin contact. It is thought that concentrations of lead in blood reflect recent exposure, while the concentrations in hair and bones reflect chronic toxicity (Kim et al., 1995). Furthermore, it has been suggested that lead can be stored in bones for up to ten years and that there is an active transfer between bone and the blood stream, especially during pregnancy and breastfeeding (Corey and Galvão, 1989). It has also been observed that lead deposits in the placenta usually reflect exposure to these metals during pregnancy (Reichrtova et al., 1998). Thus, it has been surmised that placenta could be a thin protective barrier to the fetus (lyengar and Rapp, 2001c; Durska et al., 2002; Bellinger et al., 1987).

With respect to cadmium, the main routes of contamination are via breathing and consumption of contaminated food and water (International Programme on Chemical Safety (IPCS), 1992). Smokers are the most exposed due to the amount of cadmium in cigarettes (Florek et al., 2004; Falcon et al., 2003). Elevated concentrations of cadmium in the human body cause severe stomach and lung alterations, which in turn increase the risk of death due to respiratory insufficiency (Nordberg, 2004). Acute intoxication causes abdominal pain, nausea and diarrhea whereas chronic exposures to low levels of cadmium can produce kidney damage, pulmonary emphy-sema, lung cancer, hypertension, liver and testicles damage, and alterations to the immune and nervous systems (IPCS, 1992). It has been observed that cadmium concentrations in the placenta of pregnant women are higher than those in both maternal blood and umbilical cord blood and that maternal blood concentration are lower than those in umbilical cord blood, showing that this organ appears to be a protective barrier (IPCS, 1992; Nakano et al., 1989; Galicia-Garcia et al., 1997).

Less is known about the placental transfer of cadmium and its possible fetal effects than is known about lead. How the metabolism and transport of these metals is linked is not well understood, or is clear what effects are due to toxicity per se or to deprivation of essential metals (Goyer, 1995). How the placenta functions as a barrier to cadmium is not well understood. The essential minerals in fetal blood are similar to or even higher than those of the mother, but for toxic minerals the placenta would have protective functions. The placenta constitutes an effective barrier against cadmium (Nakano et al., 1989) and lead (Korpela et al., 1986; Romero et al., 1990; Plockinger et al., 1993; Phuapradit et al., 1994; Dussias et al., 1997; Li et al., 2000).

In Peru, it has been reported that the mean blood lead levels of adults living in a section of Lima and in some
Andean cities are higher than the upper safety limit is 10 ug/dl (Ramirez et al., 1997). Another study on adult workers occupationally exposed and furnace workers of the metallurgic town of La Oroya showed cadmium blood concentrations greater than $10 \mathrm{ug} / \mathrm{dl}$ (Gomez and Lizano, 1977). To our knowledge, there is only one study completed in La Oroya which has shown that pregnant women have high mean blood lead concentrations (Unión para el Desarrollo Sustentable de la Provincia de Yauli La Oroya (UNES), 1999). Therefore, a study was conducted to confirm contamination with lead and cadmium in pregnant women and transfer of these metals to the fetus during pregnancy. The specific objective was to determine the lead and cadmium concentration in maternal and umbilical cord blood and placental tissue and breast milk in women living in a mining-smelting town in Peru.

\section{MATERIALS AND METHODS}

\section{Study location and duration}

Yauli (La Oroya) is a district with approximately 58,990 inhabitants in 2002 (Instituto Nacional de Estadística e Informática (Peru), 2009) living near poly-metals refining and melting plants. The city is located at 3,730 meters above sea level and it is geographically divided into three well-known sections: Old La Oroya, where the furnace is located, New La Oroya, where the actual refinery is located, and other areas mostly around the city. Approximately 8,000 women at fertile age were exposed to pollution with lead and other heavy metals. Sample collection was carried out at Hospital II ESSALUD in the city of La Oroya. The sample collection stage was completed in a period of 4 months; from October, 2003 to January, 2004. Sample processing was carried out between February and April, 2004. The analyses of lead and cadmium concentration were realized in Peruvian Institute of Nuclear Energy Chemistry laboratory.

\section{Study design}

The design corresponds to a prospective cross-sectional study, considering that the evaluation of the 40 deliveries and sampling of maternal and umbilical cord blood and placental tissue samples were completed in only one stage.

\section{Study population}

The study was conducted in pregnant women who had normal pregnancies ( $\geq 37$ weeks), had been residing for at least one year in the city of La Oroya and had sought medical attention at the Hospital II of ESSALUD. This hospital normally attends to $90 \%$ of the births in the city. The study sample included all pregnant women who wanted to participate voluntarily in the study and who had received attention during childbirth at the hospital. Women were included into the study if they complied with the following criteria: normal pregnancy ( $>37$ weeks) had been living for at least one year in La Oroya, with no past-history of chronic illnesses, and were voluntarily willing to accept to be part of the study. At the end of the field study, 40 subjects who had complied with the study 
Table 1. Results of reference materials $\left(\mathrm{mg}^{\mathrm{kgg}}{ }^{-1}\right.$, dry weight $)(n=6)$.

\begin{tabular}{ccccc}
\hline \multirow{2}{*}{ Element } & \multicolumn{2}{c}{ Dogfish muscle } & \multicolumn{2}{c}{ Simulated diet $\mathbf{F}$} \\
\cline { 2 - 5 } & Lab value & RM value & Lab value & RM value \\
\hline $\mathrm{Cd}$ & $0.044 \pm 0.010$ & $0.043 \pm 0.008$ & $0.92 \pm 0.20$ & $0.877 \pm 0.045$ \\
$\mathrm{~Pb}$ & $0.068 \pm 0.010$ & $0.065 \pm 0.007$ & $0.477 \pm 0.070$ & $0.439 \pm 0.026$ \\
\hline
\end{tabular}

criteria were evaluated. These women lived either in Old Oroya, New Oroya or other area of the city. All subjects provided informed signed consent before their participation.

\section{Sample collection and analysis}

Maternal blood samples $(10 \mathrm{ml})$ were taken before birth. After the reception of the newborn, $10 \mathrm{ml}$ of blood of the umbilical cord was taken when the placenta was still in-uterus. In all cases was collected $10 \mathrm{ml}$ of blood using tubes with anticoagulant and mineral free. All samples were then coded and stored in a freezer $\left(-18^{\circ} \mathrm{C}\right)$ until processing. Placenta was dried with sterile gauze and divided into four quadrants, taking samples of $50 \mathrm{~g}$ of each quadrant in order to have $200 \mathrm{~g}$ of fresh sample, which was placed in sterile bags and carried freezing, following the method by lyengar et al. $(2001 \mathrm{a}, \mathrm{b})$. Breast milk samples were taken by extraction on the thirteenth day of delivery. Samples were transported to the Lima city every weekend for storage until the field work was completed.

All maternal and umbilical cord blood samples and placental tissue samples were unfrozen, placental tissue samples were dried and grinded, following the recommendations of lyengar et al. (2001a, b, c). The drying was done by placing the samples in a Petri dish and heating them in a stove for $6 \mathrm{~h}$ at $70^{\circ} \mathrm{C}$ (Association of Official Analytical Chemists (AOAC), 2000). The dried samples were afterwards grinded by placing them in a double paper bag and using glass rollers for manual pressure grinding. The finely grinded samples were then stored in $5 \mathrm{ml}$ glass bottles which had been previously washed with de-ionized water and transported to the Chemistry laboratory for analysis (lyengar and Rapp, 2001b, c; lyengar, 1997). Three hundred $\mathrm{mg}$ of sample was digested with nitric and perchloric acids ultrex quality. Then samples were diluted to $10 \mathrm{ml}$ with pure water. Palladium matrix modifier and Zeeman background correction were used in the analysis. Analytical blanks were also considered. Two reference materials, DORM-2 dogfish muscle and Simulated diet $\mathrm{F}$ were used to ensure the quality data produced in the analysis of plasma and breast milk, respectively. The good agreements with the obtained results provide quality assurance to the reported data (Table 1).

\section{Statistical analysis}

Data analysis was done using the statistical software (SPSS V.15). Associations between variables were examined by Pearson's correlation analysis. Analysis of variance (ANOVA) was used to compare differences in mother's age, years of residency, and number of previous births, birth weight of the infant and lead and cadmium concentrations in maternal blood, maternal milk, placenta and umbilical cord between the three geographical areas within $\mathrm{La}$ Oroya. Multivariate stepwise and linear regression analyses were used to determine whether mother's age, place of residency, years of residency, and number of previous births or the birth weight and sex of the infant predicted lead or cadmium concentrations in maternal blood. A second set of models, which also included maternal blood concentrations, were used to predict concentrations in placenta. A third set of models, which also included concentrations in placenta, were used to predict concentrations in the umbilical cord. In addition, linear and stepwise regression analyses were used to assess whether mother's age, place of residency, years of residency and maternal lead concentrations predicted maternal breast milk concentrations. Finally, linear and stepwise regression analyses were used to determine which variables predicted the birth weight of the neonates.

\section{Ethical aspects of the study}

The protocol was reviewed by the research committee of the Institute of Agrarian University La Molina. All pregnant women were informed of study and they expressed consent for their voluntary participation and their cooperation in this study.

\section{RESULTS}

\section{Subject characteristics}

The characteristics of the study population are shown in Table 2. Out of the women studied, nine were from Old La Oroya, twenty-one from New La Oroya and ten from other areas of the city, but their work was confined to Old La Oroya. There were no significant differences in the age, years of residency or the birth weight or sex of the children between the three groups of women.

\section{Lead and cadmium concentrations}

Mean lead and cadmium concentrations are shown in Table 3. In general, the mean \pm standard deviation (SD) lead blood concentration of women was $27.2 \pm 15.9$ $\mu \mathrm{g} / \mathrm{dl}$, with 33 out of $40(82.5 \%)$ having blood lead concentrations above the recommended upper safety limit of $10 \mu \mathrm{g} / \mathrm{dl}$. Similarly, the mean \pm SD lead concentration in blood of neonates (that is, the umbilical cord blood) was $18.5 \pm 13.0 \mu \mathrm{g} / \mathrm{dl}$, with 26 out of $40(65 \%)$ having lead concentrations above the aforementioned recommended upper safety limit. The mean \pm SD placenta lead concentration was $364.0 \pm 314.5 \mu \mathrm{g} / \mathrm{dl}$. Furthermore, the mean $\pm S D$ maternal milk lead concentration was $108.9 \pm$ $69.4 \mu \mathrm{g} / \mathrm{dl}$, which also was significantly higher than that for maternal blood $(p<0.001)$.

On the other hand, mean $\pm S D$ cadmium blood concentrations in women were lower than that for lead $(8.8 \pm 7.0$ $\mu \mathrm{g} / \mathrm{dl})$, but 18 out of $40(45 \%)$ had blood cadmium 
Table 2. Characteristics of the study population by geographical area.

\begin{tabular}{lcccc}
\hline Variable & $\begin{array}{c}\text { Total } \\
(\mathbf{n}=\mathbf{4 0})\end{array}$ & $\begin{array}{c}\text { Old La Oroya } \\
(\mathbf{n}=\mathbf{9})\end{array}$ & $\begin{array}{c}\text { New La Oroya } \\
(\mathbf{n}=\mathbf{2 1})\end{array}$ & $\begin{array}{c}\text { Other areas } \\
(\mathbf{n}=\mathbf{1 0})\end{array}$ \\
\hline Age of mother $(\mathrm{y})^{1}$ & $28.9 \pm 5.6$ & $29.7 \pm 5.0^{\mathrm{a}}$ & $27.8 \pm 5.7^{\mathrm{a}}$ & $30.7 \pm 5.8^{\mathrm{a}}$ \\
Years of residency $^{1}$ & $16.5 \pm 10.6$ & $18.7 \pm 12.5^{\mathrm{a}}$ & $15.2 \pm 10.2^{\mathrm{a}}$ & $17.2 \pm 10.3^{\mathrm{a}}$ \\
Number of previous births ${ }^{1}$ & $1.6 \pm 1.4$ & $2.1 \pm 1.5^{\mathrm{a}}$ & $1.1 \pm 1.0^{\mathrm{b}}$ & $2.1 \pm 1.5^{\mathrm{a}}$ \\
Birth weight of child $(\mathrm{g})^{1}$ & $3186.8 \pm 393.7$ & $3253.3 \pm 482.8^{\mathrm{a}}$ & $3102.4 \pm 374.3^{\mathrm{a}}$ & $3304.0 \pm 341.5^{\mathrm{a}}$ \\
Sex of child & $22 \mathrm{M} / 18 \mathrm{~F}$ & $4 \mathrm{M} / 5 \mathrm{~F}$ & $14 \mathrm{M} / 7 \mathrm{~F}$ & $4 \mathrm{M} / 6 \mathrm{~F}$ \\
\hline${ }^{1}$ Means with the same superscript within geographical area are not significantly different $(\mathrm{p}>0.05$, Tukey's test). M: Male \\
F: Female.
\end{tabular}

Table 3. Mean $\pm S D$ lead and cadmium concentrations of maternal blood, milk, placenta and umbilical cord blood $(n=40)$.

\begin{tabular}{lcc}
\hline Variable & Lead $($ Mean \pm SD) & Cadmium (Mean \pm SD) \\
\hline Maternal blood $(\mu \mathrm{g} / \mathrm{dl})$ & $27.2 \pm 15.9$ & $8.8 \pm 7.0$ \\
Placenta $(\mathrm{ng} / \mathrm{g})$ & $364.0 \pm 314.5$ & $104.4 \pm 108.9$ \\
Umbilical cord blood $(\mu \mathrm{g} / \mathrm{dl})$ & $18.5 \pm 13.0$ & $12.0 \pm 17.8$ \\
Maternal milk $(\mu \mathrm{g} / \mathrm{dl})$ & $108.9 \pm 69.4$ & $5.6 \pm 4.3$ \\
\hline
\end{tabular}

concentrations above the recommended upper safety limit of $10 \mu \mathrm{g} / \mathrm{dl}$. Similarly, the mean $\pm S D$ cadmium blood concentration of neonates was also lower than that for lead $(12.0 \pm 17.8 \mu \mathrm{g} / \mathrm{dl})$, but 15 out of $40(37.5 \%)$ had cadmium concentrations above the recommended upper safety limit. The mean \pm SD placenta cadmium concentration was $104.4 \pm 108.9 \mu \mathrm{g} / \mathrm{dl}$. The mean $\pm S D$ maternal milk cadmium concentration was $5.6 \pm 4.3 \mu \mathrm{g} / \mathrm{dll}$, which was significantly lower than that for maternal blood.

No significant correlations were found between lead concentrations in maternal blood and lead concentrations in maternal milk, place of residency, years of residency, number of previous births, and sex or birth weight of the child. Nevertheless, a significant positive correlation was found between maternal lead blood concentrations and umbilical cord concentrations ( $p=0.042)$ (Figure 1).

Furthermore, after excluding possible outliers, a significant positive correlation was also observed between lead in maternal blood and lead in placenta $(p<0.001)$ (Figure 2). Regarding cadmium, no significant correlations were found between cadmium concentrations in maternal blood and cadmium concentrations in umbilical cord or maternal milk, place of residency, years of residency, number of previous births, and sex or birth weight of the child. A positive and significant relationship was observed between maternal blood cadmium concentrations and placenta cadmium concentrations $(p<0.001)$ (Figure 3$)$.

Mean lead and cadmium concentrations by geographical region are shown in Table 4. There were no significant differences in the mean lead concentration in maternal blood, maternal milk or placenta between the three different geographical areas of La Oroya. The mean lead concentration in the umbilical cord appeared to be lower in New La Oroya compared to Old La Oroya and other areas, but this difference was slightly nonsignificant $(13.9 \pm 12.0$ versus $22.6 \pm 9.4$ and $24.4 \pm 15.1$ $\mu \mathrm{g} / \mathrm{dl}$, respectively; $\mathrm{p}=0.58)$. On the other hand, the mean cadmium concentration in the blood of women living in Old La Oroya was significantly higher than that of the women who lived in New La Oroya (14.1 \pm 6.5 versus $7.1 \pm 7.3$, respectively; $p=0.029$ ). Furthermore, the mean concentration of cadmium in the umbilical cord of neonates of New La Oroya was significantly lower than that for neonates of the other areas $(24.1 \pm 15.2$ versus $3.7 \pm 4.3 \mu \mathrm{g} / \mathrm{dl}$, respectively; $p=0.005$ ).

\section{Trans-placental transfer of lead and cadmium}

Regarding the trans-placental transport of lead and cadmium in pregnant women of La Oroya, for the lead it was $67.8 \%(27.2 \mathrm{ug} / \mathrm{dl}$ in maternal blood versus 18.5 $\mathrm{ug} / \mathrm{dl}$ in umbilical cord blood) whereas cadmium of umbilical cord blood was $36.4 \%$ more that in maternal blood $(8.8 \mathrm{ug} / \mathrm{dl}$ in maternal blood versus $12.0 \mathrm{ug} / \mathrm{dl}$ inumbilical cord blood). Concentrations of lead in maternal blood were significantly higher than those for the umbilical cord blood $(p=0.002)$. On the other hand, 


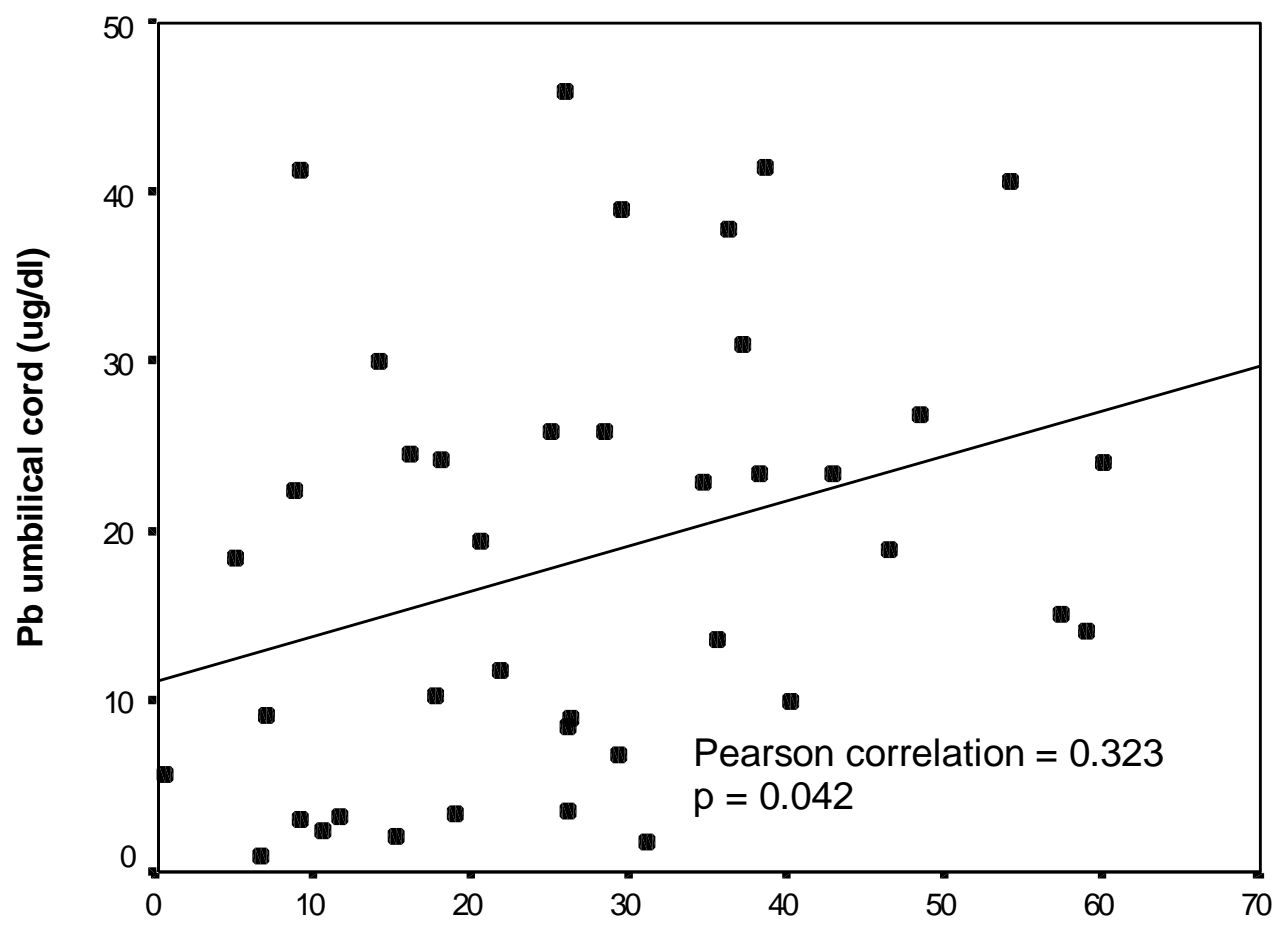

$\mathrm{Pb}$ maternal blood (ug/dl)

Figure 1. Relationship between lead concentration in maternal blood and umbilical cord blood.

Table 4. Mean \pm SD lead and cadmium concentrations of maternal blood, milk, umbilical cord blood and placenta of women by geographical region within La Oroya $(n=40)$.

\begin{tabular}{lcccc}
\hline Variable & $\begin{array}{c}\text { Old La Oroya } \\
(\mathbf{n}=9)\end{array}$ & $\begin{array}{c}\text { New La Oroya } \\
(\mathbf{n}=\mathbf{2 1})\end{array}$ & $\begin{array}{c}\text { Other areas } \\
(\mathbf{n}=\mathbf{1 0})\end{array}$ & $\mathbf{p}$ \\
\hline Lead & & & & \\
Maternal blood $(\mu \mathrm{g} / \mathrm{d} \mathrm{l})$ & $36.9 \pm 14.5^{\mathrm{a}}$ & $23.8 \pm 17.2^{\mathrm{a}}$ & $25.7 \pm 11.5^{\mathrm{a}}$ & 0.110 \\
Placenta $(\mathrm{ng} / \mathrm{g})$ & $547.8 \pm 393.4^{\mathrm{a}}$ & $285.4 \pm 251.5^{\mathrm{a}}$ & $363.6 \pm 320.0^{\mathrm{a}}$ & 0.110 \\
Umbilical cord blood $(\mu \mathrm{g} / \mathrm{dl})$ & $22.6 \pm 9.4^{\mathrm{a}}$ & $13.9 \pm 12.0^{\mathrm{a}}$ & $24.4 \pm 15.1^{\mathrm{a}}$ & 0.058 \\
Maternal milk $(\mu \mathrm{g} / \mathrm{dl})$ & $122.7 \pm 21.1^{\mathrm{a}}$ & $102.2 \pm 89.4^{\mathrm{a}}$ & $110.6 \pm 49.0^{\mathrm{a}}$ & 0.770 \\
& & & & \\
Cadmium & & & & \\
Maternal blood $(\mu \mathrm{g} / \mathrm{dl})$ & $14.1 \pm 6.5^{\mathrm{a}}$ & $7.1 \pm 7.3^{\mathrm{b}}$ & $7.7 \pm 4.4^{\mathrm{ab}}$ & 0.032 \\
Placenta $(\mathrm{ng} / \mathrm{g})$ & $169.3 \pm 76.3^{\mathrm{a}}$ & $89.3 \pm 114.7^{\mathrm{a}}$ & $77.8 \pm 106.8^{\mathrm{a}}$ & 0.120 \\
Umbilical cord blood $(\mu \mathrm{g} / \mathrm{dl})$ & $18.0 \pm 28.9^{\mathrm{ab}}$ & $3.7 \pm 4.3^{\mathrm{a}}$ & $24.1 \pm 15.3^{\mathrm{b}}$ & 0.004 \\
Maternal milk $(\mu \mathrm{g} / \mathrm{dl})$ & $6.2 \pm 6.3^{\mathrm{a}}$ & $4.8 \pm 1.8^{\mathrm{a}}$ & $6.9 \pm 5.7^{\mathrm{a}}$ & 0.420 \\
\hline
\end{tabular}

Means with different superscript are significantly different ( $p \leq 0.05$, Tukey's test).

the concentrations of cadmium in the umbilical cord blood were not significantly different than those for maternal blood. Finally, the concentrations of both lead and cadmium were significantly higher in placenta than in maternal and umbilical cord blood $(p<0.001)$.

\section{Regression analyses}

The linear and stepwise regression models used to predict the concentration of lead in maternal blood were not significant. The same was observed for the linear and 


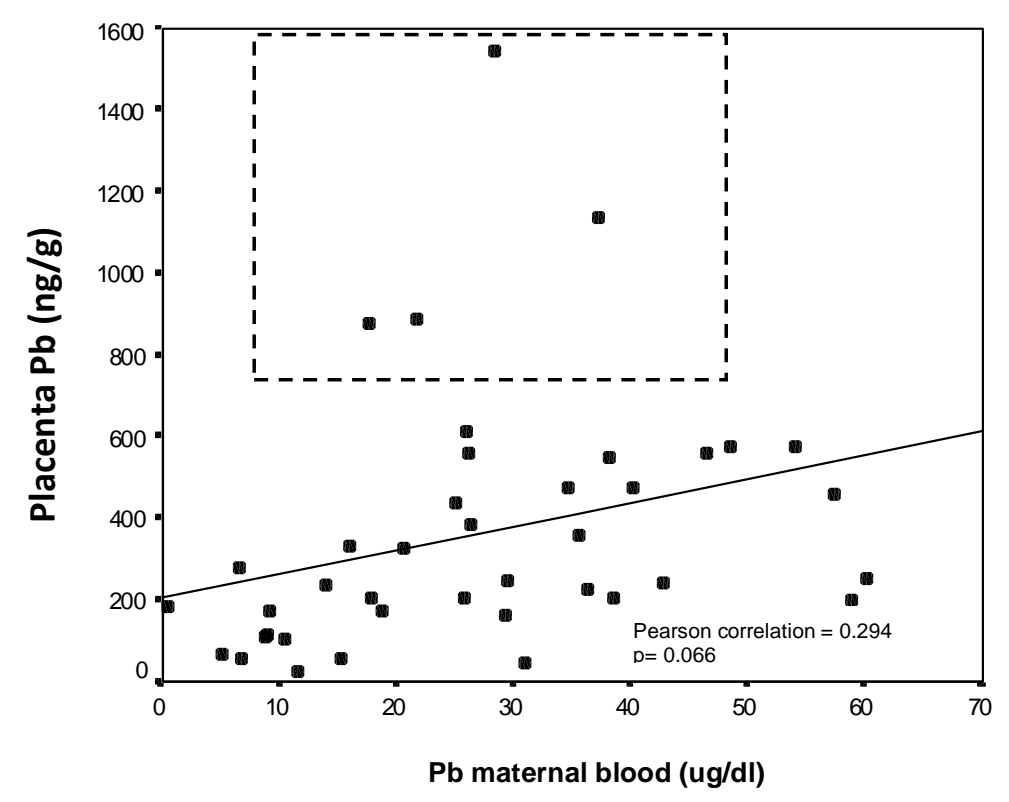

(a)



(b)

Figure 2. Relationship between lead concentration in maternal blood and lead concentration in placenta. (a) Includes all subjects and (b) excludes possible outliers (within dotted region of a).

stepwise models used to predict the concentration of lead in placenta. Nevertheless, maternal lead concentrations showed a tendency to positively predict levels of lead in placenta, given that its coefficient was only marginally non-significant $(p=0.06)$. On the other hand, the linear model used to predict lead concentration in the umbilical cord blood was significant $(p=0.008)$, with age of the mother, number of births, and lead concentration in maternal blood having significant contributions to the model (Table 5). However, when the same variables were included in the stepwise regression model, only maternal blood concentrations positively predicted the concentration of lead in umbilical cord blood ( $p=0.042$ ) (Table 5). The linear model used to predict the concentration of cadmium in maternal blood was not significant. Nevertheless, when the same variables were included in 


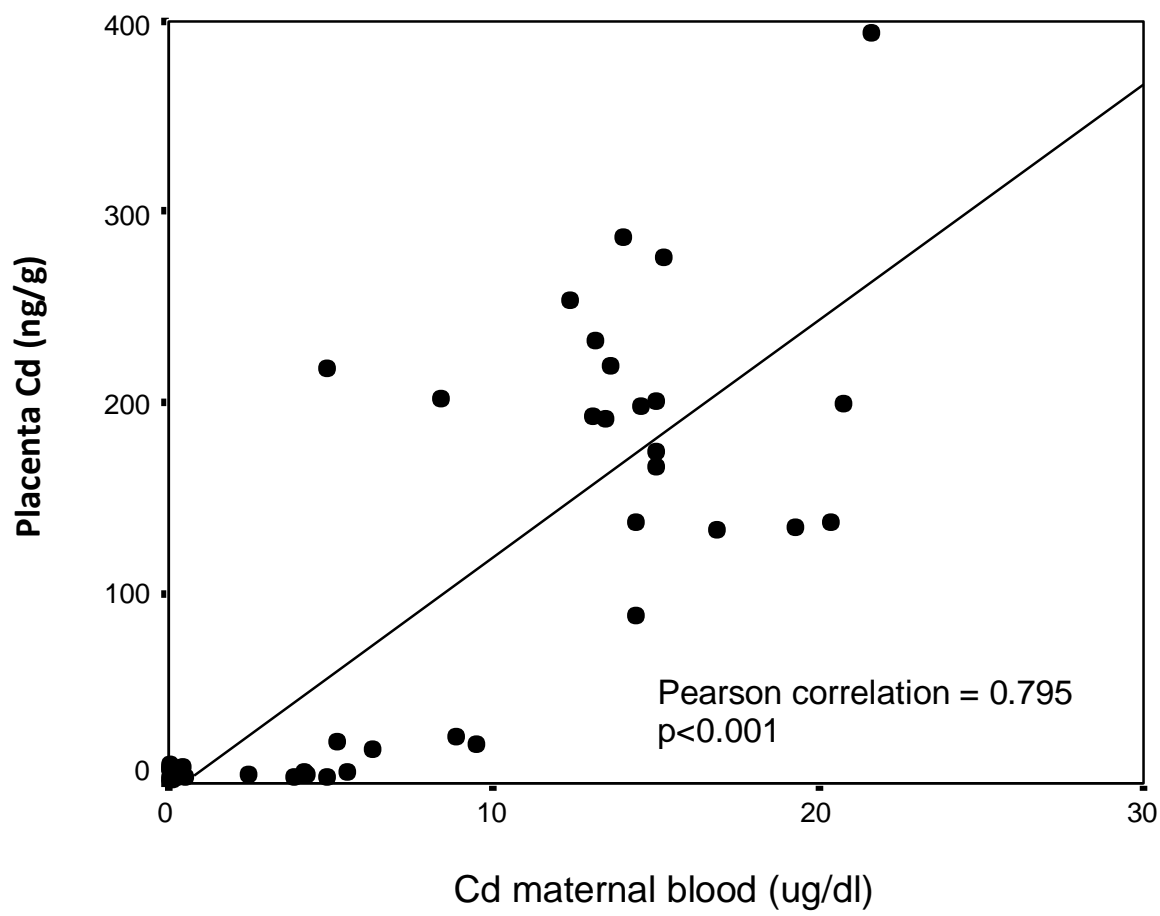

Figure 3. Relationship between cadmium concentration in maternal blood and placenta.

Table 5. Linear (A) and stepwise $(B)$ regression standardized coefficients of lead in maternal blood, lead in placenta, place of residence, years of residence, age of mother, number of births on umbilical cord blood lead concentration ${ }^{1}$.

\begin{tabular}{lcc}
\hline Variable & B coefficient & P \\
\hline A. Linear regression analysis & & \\
Lead in maternal blood & 0.32 & 0.039 \\
Lead in placenta & 0.03 & 0.82 \\
Place of residency & 0.19 & 0.19 \\
Years of residency & 0.13 & 0.39 \\
Age of mother & -0.48 & 0.013 \\
Number of births & 0.39 & 0.035 \\
& & \\
B. Stepwise regression analysis & & \\
Lead in maternal blood & 0.32 & 0.042 \\
Lead in placenta & 0.08 & 0.64 \\
Place of residency & 0.15 & 0.37 \\
Years of residency & 0.07 & 0.68 \\
Age of mother & -0.10 & 0.52 \\
Number of births & 0.08 & 0.61 \\
\hline
\end{tabular}

(A) ${ }^{1} \mathrm{p}$-value of model $=0.008$, (B) ${ }^{1} \mathrm{p}$-value of model $=0.042$.

the stepwise regression the variable place of residency of the women was only marginally non-significant as a pre- dictor $(p=0.052)$. The linear model used to predict cadmium concentration in the placenta was significant $(p$ $<0.001$ ), with cadmium concentration in maternal blood being the only variable to significantly contribute to the model (Table 6). The same results were obtained after the stepwise regression model was used. Neither model used to predict the concentration of cadmium in umbilical cord blood was significant. Neither the linear or stepwise regression models, with place of residence, years of residence, age of mother and maternal blood concentrations as independent variables, explained lead or cadmium concentrations in breast milk. None of the variables related to lead predicted birth weight, although the concentrations in umbilical cord were only marginally non-significant $(p=0.07)$.

Furthermore, none of the variables related to cadmium predicted birth weight. However, when all variables were included in the same model, there was negative and significant relationship between birth weight of the neonate and lead concentrations in the umbilical cord blood $(p=0.04)$.

All regression analyses were repeated, but only including those mothers with blood lead and cadmium concentrations above the upper safety limit of $10 \mu \mathrm{g} / \mathrm{dl}$. Interestingly, the number of years of residency showed a tendency to predict maternal lead concentrations, although this was marginally non-significant $(p=0.07)$. On the other hand, the number of previous births was 
Table 6. Linear regression standardized coefficients of cadmium in maternal blood, age of mother, place of residency, number of previous births, birth weight of infant, and sex of infant on placenta cadmium concentration ${ }^{1}$.

\begin{tabular}{lcc}
\hline Variable & B coefficient & $\mathbf{p}$ \\
\hline Cadmium in maternal blood & 0.798 & $<0.001$ \\
Age of mother & -0.039 & 0.790 \\
Place of residency & -0.033 & 0.770 \\
Number of previous births & 0.156 & 0.270 \\
Birth weight of infant & -0.011 & 0.920 \\
Sex of infant & -0.124 & 0.290 \\
\hline
\end{tabular}

${ }^{1} \mathrm{p}$-value for model $<0.001$.

positively related to the levels of cadmium in placenta $(p$ $=0.005$ ). Finally, a negative and significant relationship between birth weight and lead concentrations in the umbilical cord blood was found $(p=0.006)$, which became stronger if the variable years of residency was also included in the model $(p=0.002)$.

\section{DISCUSSION}

Environmental contamination of heavy metals, such as lead and cadmium, is a health risk with many adverse consequences (Andrews et al., 1994; Bellinger et al., 1987; Corey and Galvão, 1989; Dudek, 1993; Falcon et al., 2003; Nordberg, 2004). This is especially true for populations living in metallurgic cities (Baghurst, 1992; Mahaffey et al., 1983). The results of this study indicate that a proportion of pregnant women who live in La Oroya, a Peruvian city with both poly-metals refining and melting plants, have high concentrations of lead and/or cadmium in their blood. Furthermore, $65 \%$ of neonates had high umbilical cord blood lead concentrations and $38 \%$ had high cadmium concentrations in umbilical cord blood.

The mean concentration of lead in the blood of the women of this study is similar, but somewhat lower than those found by previous studies conducted in the same area (Ramirez et al., 1997; UNES, 1999). On the other hand, the mean cadmium concentrations were comparable to those found on one previous study (Gomez and Lizano, 1977). Thus, it seems that the population of La Oroya does suffer from chronic contamination of heavy metals. Given that the city is geographically divided into three distinct areas in relation to their closeness to the mining melting plant, the study also attempted to determine whether lead and/or cadmium toxicity were related to the geographical location of the different areas of the city. Nevertheless, no clear relationship was found between geographical location with lead and cadmium concentrations in pregnant women, even though the three groups were comparable with respect to age and the number of years of residency in La Oroya. It is possible that this occurred because the study population lived scattered throughout the city and not directly in the path of the fumes blown by the wind. On the other hand, it is also possible that the sample size was not big enough to detect differences between the three areas.

Given that it was observed that the concentrations of both lead and cadmium were significantly higher in the placenta than both maternal and umbilical cord blood, it would appear that the placenta does retain these metals during pregnancy and act as a protective barrier to the fetus. This appeared to be especially true for lead, given that the trans-placental transfer to the fetus was around $68 \%$ and that the concentration of lead in the umbilical cord blood was significantly lower in the umbilical cord blood compared to maternal blood. The trans-placental lead gradient found in this study is somewhat lower than that found in other populations (Durska et al., 2002; Bellinger et al., 1987; Dussias, 1997). On the other hand, it was not as clear in the case of cadmium as the concentrations of this metal in umbilical cord blood were similar to those in maternal blood and the trans-placental transfer was very high, $36 \%$ more to the mothers.

Nevertheless, it should be noted that lead and cadmium deposits in the placenta appear to reflect exposure to these metals throughout the pregnancy period, while it is thought that concentrations of lead in blood reflect more recent exposure. All of this does not take away the fact that the mean concentration of both lead and cadmium in the umbilical cord blood were higher than the upper safety limit indicating that toxicity of these metals occurs and they are being transferred to the fetus during pregnancy; results confirm reports that said the maternal blood lead easily crosses the placenta and its level in umbilical cord blood is similar to mother (Goyer, 1990; Romero et al., 1990; Li et al., 2000; Furman and Laleli, 2001; Druska et al., 2002) and for cadmium case, what is clear in this research is that the placenta plays a complex and active role in reducing transfer of cadmium from mother to fetus. Studies relating maternal and umbilical cord blood cadmium levels have shown that there is a maternal-fetal gradient and that the placenta serves as a partial barrier to transplacental transport of cadmium (Goyer, 1991; Nakano et al., 1989).

It appears that the concentration of lead in maternal blood during pregnancy could predict the expected concentration of this metal in the umbilical cord blood. Nevertheless, the same was not observed for cadmium. On the other hand, when the analyses were done with only those women who had blood concentrations considered toxic, the number of years of residency in the area tended to predict the concentration of lead in maternal blood. It is possible that the sample size of the 
study hindered these analyses. We found that the concentration of lead in breast milk was high, significantly higher than that of maternal blood, which could indicate that lead is accumulating in the mammary gland. Therefore, the newborns received significant amounts of lead not only the mother, through the placenta, but in breast milk after birth.

Interestingly, the birth weights of the study children were in general normal, only two children (5\%) having low birth weight. Nevertheless, a negative and significant relationship between birth weight of the neonate and lead concentrations in the umbilical cord blood was observed. Similar results has been reported by other authors (Bellinger et al., 1991; Gonzales-Cossio et al., 1997; Kaul et al., 2002). In this, there are conflicting reports on effect of fetal lead exposure and birth weight. Certain works have reported an increase in birth weight (Factor-Litvak et al., 1991; Wang et al., 1989) while others have reported either no effect or decrease (Nordstrom et al., 1979; McMichael et al., 1986). Furthermore, the relationship appears to be stronger if only those women with toxic levels of lead in blood are included in the analysis. This observation is consistent with at least one previous study, which showed the same relationship between these two variables (Lopez-Lara et al., 2000).

\section{Conclusion}

It is evident that the population living in La Oroya have a serious problem of environmental contamination with heavy metals, as exemplified by the levels of lead and cadmium observed in the blood of pregnant women and their neonates. Furthermore, although it seems that the placenta might act as a protective barrier to the fetus, it appears that in this population the fetus is still being irrigated with blood which contains high levels of both lead and cadmium. Our results suggest that the amount of lead and cadmium accumulated in placenta and their transfer to fetus is strongly influenced by the lead and cadmium body burden of the mother. Finally, although in general the birth weights of the neonates were normal, these had a negative relationship with the concentration of lead in the umbilical cord, which might be cause for concern.

\section{REFERENCES}

AOAC (2000). Official Methods of Analysis of AOAC International Association of Official Analytical Chemists. $17^{\text {th }}$ edition. Washington D.C. USA.

Andrews KW, Savitz DA, Hertz-Picciotto I (1994). Prenatal lead exposure in relation to gestational age and birth weight: a review of epidemiological studies. Am. J. Ind. Med. 26:13-32.

Baghurst PA (1992). Environmental exposure to lead and children's intelligence at the age of seven years: the port Pirie cohort study. New England Journal of Medicine. 327:1279-1284.

Bellinger D, Leviton A, Waternaux C, Needleman H, Rabinowitz M (1987). Longitudinal analyses of prenatal and postnatal lead exposure and early cognitive development. N. Engl. J Med. 316:1037-1043.

Bellinger D. Leviton A, Rabinowitz M, Allred E, Needleman H, Schenbaum S (1991). Weight gain and maturity in fetuses exposed to low levels of lead. Environmental Research. 54 (2/Apr.):151-158.

Corey G, Galvão L (1989). Lead. Vigilance Series 8. Pan-American Center for Human and Health Ecology. PAHO/WHO. Mexico.

Dudek B (1993). Toxic effects of lead in children. Med Pr. 44 (6 suppl 1):102-14.

Durska G, Kozielec T, Karakiewicz B (2002). Evaluation of transplacental gradient for cadmium and lead. Ginekol Pol. 73:43-9.

Dussias V, Stefos T, Stefanidis K, Paraskevaidis E, Karabini F, Lolis D, Vasilios D, Theodor S, Konstantinos S, Evangelos P, Fotini K, Dimitrios L (1997). Lead concentrations in maternal and umbilical cord blood in areas with high and low air pollution. Clin Exp Pbstet Gynecol. 24(4):187-9.

Factor-Litvak P, Graziano JH, Kline JK. Popvac D, Mohmeti A, Ahmedi A (1991). A prospective study of birth weight and length of gestation in a population around a lead smelter in Kosovo, Yugoslavia. Int. J. Epidemiol. 20:722-728.

Falcon M, Vinas P, Perez-Carceles MD, Luna A (2003). Placental cadmium and lipid peroxidation in smoking women related to newborn anthropometric measurements. Arch Environ. Contam. Toxicol. 45:278-82.

Furman A, Laleli M (2001). Maternal and umbilical cord blood lead levels: an Istanbul study. Arch. Environ. Health. 56(1):26-8.

Florek E, Piekoszewski W, Kornacka MK, Koroniak H, Wolna M, Krol A (2004). Determination of cadmium in urine of tobacco smoking pregnant women. Przegl Lek. 61:1109-12.

Galicia-Garcia V, Rojas-Lopez M, Rojas R, Olaiz G, Rios C (1997). Cadmium levels in maternal, cord and newborn blood in Mexico City. Toxicol Lett. 91:57-61.

Gomez J, Lizano J (1977). Blood arsenic, cadmium and copper in the workers of the "Mineral Metallurgical Center" of La Oroya. Toxicological Lab and Legal Chemistry of the Faculty of Pharmacy and Biochemistry of UNMSM. Lima. Peru.

Gonzalez-Cossio T, Peterson K, Sanin LH, Fishbein E, Palazuelos E, Aro A, Hernandez-Avila M, Hu H (1997). Decrease in birth weight in relation to maternal bone-lead burden. Pediatrics Vol. 100 (5)1:856862.

Goyer RA (1990). Transplacental transport of lead. Environ. Health Perspect. 89:101-5.

Goyer RA (1991). Transplacental transfer of cadmium and fetal effects. Fundam. Appl. Toxicol. 16:22-23.

Goyer RA (1995). Nutrition and metal toxicity. Am. J. Clin. Nutr. 61(3 Suppl):646S-650S.

INEI (2009). Peru: Estimates and projections of population by sex, by department, province and district - 2000-2015. National Institute of Statistics. Peru. Available in: http://www.inei.gob.pe/biblioineipub/bancopub/Est/Lib0842/.

IPCS (1992). Cadmium. Environmental Health Criteria 134. International Programme on Chemical Safety. Geneva: World Health Organization.

lyengar GV, Rapp A (2001a). Human placenta as a 'dual' biomarker for monitoring fetal and maternal environment with special reference to potentially toxic trace elements. Part 2: Essential minor, trace and other (non-essential) elements in human placenta. The Science of the Total Environment. 280:207-219.

Iyengar GV, Rapp A (2001b). Human placenta as a 'dual' biomarker for monitoring fetal and maternal environment with special reference to potentially toxic trace elements. Part 1: Physiology, function and sampling of placenta for elemental characterization. Sci. Total Environ. 280:195-206.

lyengar GV, Rapp A (2001c). Human placenta as a 'dual' biomarker for monitoring fetal and maternal environment with special reference to potentially toxic trace elements. Part 3: Toxic trace elements in placenta and placenta as a biomarker for these elements. Sci.Total Environ. 280:221-38.

lyengar, GV (1997). Sampling and processing of biological and environmental specimens for compositional studies: Issues and perspectives. Harmonization of Health Related Environmental 
Measurements Using Nuclear and Isotopic Techniques, IAEA-SM344/19, Viena.

Kaul P, Srivastava R, Srivastava SP, Kamboj M, Chand S (2002). Relationships of maternal blood lead and disorders of pregnancy to neonatal birthweight. Vet. Hum. Toxicol. 44(6):321-3.

Kim R, Hu H, Rotnitzky A, Bellinger D, Needleman HL (1995). A longitudinal study of chronic lead exposure and physical growth in Boston children. Environ. Health Perspect. 103:952-7.

Korpela H, Loueniva R, Yrjanheikki E, Kauppite A (1986). Lead and cadmium concentration in maternal and umbilical cord blood, amniotic fluid, placenta, and amniotic membranes. Am. J. Obstet. Gynecol. 155(5):1086-9.

Li PJ, Sheng YZ, Wang QY, Gy LY, Wang YL (2000). Transfer of lead via placenta and breast milk in human. Biomed Environ. Sci. 13(2):85-9.

Lopez-Lara B, Cantú P, Hernández L, Gómez-Gúzman L (2000). Lead concentrations in the blood of the newborns and their relationship with their weight during birth. Public Health Nutr. Magazine 1(2):1-7.

Mahaffey KR (1983). Biotoxicity of lead: influence of various factors. Fed. Proc.. 42(6):1730-1734.

McMichael AJ, Vimpani GV, Robertson EF, Baghurst PA, Clark PD (1986). The Port Pirie cohort study: maternal blood lead and pregnancy outcome. J. Epidemiol. Community Health. 40(1):18-25.

Nakano A, Ono M, Ohta Y, Wakisaka I (1989). Placental transfer of cadmium in pregnant women. Nippon Eiseigaku Zasshi. 44(2):57986.

Needleman HL (1998). The persistent threat of lead: medical and sociological issues. Curr Probl Pediatr. 18: 697-744.

Nordberg GF (2004). Cadmium and health in the 21st century--historical remarks and trends for the future. Biometals. 17:485-9.

Nordstrom S, Beckman L, Nordenson I (1979). Occupational and environmental risks in and around a smelter in northern Sweden. Spontaneous abortion among female employees and decreased birth weight in their offsprings. Hereditas. 90:291-296.
Osman K, Akesson A, Berglund M, Bremme K, Schutz A, Ask K, Vahter $M$ (2000). Toxic and essential elements in placentas of Swedish women. Clin. Biochem. 33:131-138.

Phuapradit W, Jetsawangsri T, Chaturachinda K, Noinongyao N (1994). Maternal and umbilical cord blood lead levels in Ramathibod Hospital. J. Med. Assoc Thai. 77(7):386-72.

Plockinger B, Dada K, Meisinger V (1993). Lead, mercury and cadmium in newborn infants and their mothers. Geburtshilfe Perinatol. 197(2):104-7.

Ramirez, A., Cam J, Medina J (1997). Sanguine lead in the inhabitants of four Peruvian towns. Pan-American Public Health Magazine. 1(5):344-348).

Reichrtova E, Dorociak F, Palkovicova L (1998). Sites of lead and nickel accumulation in the placental tissue. Hum Exp Toxicol. 17:176-81.

Romero RA, Granadillo VA, Navarro JA, Rodriguez-Iturbe B, Pappaterra J, Pirela H (1990). Placental transfer of lead in mother/newborn pairs of Maracaibo City (Venezuela). J Trace Electrolytes Health Dis. Dec;4(4):241-3.

UNES (1999). Evaluación de Niveles de Plomo y Factores de Exposición en Gestantes y Niños Menores de 3 Años de la Ciudad de La Oroya - Perú. Consorcio Unión para el Desarrollo Sustentable de la Provincia de Yauli - La Oroya, en colaboración con el Instituto Salud y Trabajo.

Wang JD, Shy WY, Chen JS, Yang KH, Hwang YH (1989). Parental occupational lead exposure and lead concentration of cord blood. Am. J. Ind. Med. 15:111-115. 